\title{
Digital mammography in Japan
}

\section{Takayoshi Uematsu}

Published online: 14 January 2010

(C) The Japanese Breast Cancer Society 2010

\section{Foreword}

Digital mammography has been proposed as an alternative to screen-film mammography. Previous publications have reported the equivalent performance of digital and film mammography [1, 2], and digital mammography has some advantages over film mammography [3, 4],including many technical advantages, including image-enhancement capability, faster image acquisition, and better storage and transmission for archiving. Its full potential can only be achieved through soft-copy reading.

More than $70 \%$ of the facilities in Japan have digital mammography systems. However, most of the digital mammography systems use computed radiographic mammography and only about $10 \%$ of the facilities have fullfield digital mammography systems. In addition, there are few facilities with soft-copy reading of digital mammography in Japan. This situation is remarkable, because most of the digital mammography systems worldwide are fullfield digital mammography systems with soft-copy reading.

Because the soft-copy reading of digital mammography involves very complex processes, some issues have been raised. For the special articles in this issue, a group of recognized and experienced experts, based on the
Mammography Subcommittee of the Japan Radiological Society, were assembled. These experts have put together a monograph on digital mammography. The special articles provide a comprehensive review and update on digital mammography, especially in Japan. They will serve as an excellent reference source for anyone interested in digital mammography.

\section{References}

1. Lewin LM, Hendrick RE, D’Orsi CJ, Isaacs PK, Moss LJ, Karellas A, et al. Comparison of full-field digital mammography with screen-film mammography for cancer detection: results of 4,945 paired examinations. Radiology. 2001;218:873-80.

2. Skaane P, Skjennald AS. Screen-film mammography versus fullfield digital mammography with soft-copy reading: randomized trial in a population-based screening program-the Oslo 2 study. Radiology. 2004;232:197-204.

3. Pisano ED, Gatsonis C, Hendrick E, Yaffe M, Baum JK, Acharyya S, et al. Diagnostic performance of digital versus film mammography for breast-cancer screening. N Engl J Med. 2005;353:1773-83.

4. Skaane P, Hofvind S, Skjennald AS. Randomized trial of screenfilm versus full-field digital mammography with soft-copy reading in a population-based screening program: follow-up and final results of Oslo 2 study. Radiology. 2007;244:708-17.

T. Uematsu $(\bowtie)$

Department of Breast Imaging and Breast Intervention,

Breast Center, Shizuoka Cancer Center Hospital, Naga-izumi,

Shizuoka 411-8777, Japan

e-mail: t.uematsu@scchr.jp

T. Uematsu

Department of Clinical Physiology, Shizuoka Cancer Center

Hospital, Naga-izumi, Shizuoka 411-8777, Japan 